\title{
Automated process control system for closed water supply installations for fish cultivation
}

\author{
$M A$ Safin* and $E$ I Gerasimov \\ ATPP Department, Kazan State Power Engineer University, Kazan, Russia
}

\begin{abstract}
The paper describes an automated process control unit for closed water supply system for yearround fish farming in closed aquaculture farms. The operation principles and the technological process for maintaining stable fish growth conditions are discussed.
\end{abstract}

\section{Introduction}

Today most of the businessmen reconsidered their attitude to agriculture, and as a result its various branches began to develop promptly. One of the directions, which recently began to grow quite actively, is the fish breeding. Unfortunately, the severe climate of Russia was often an obstacle for rapid growth and cultivation of fish in the traditional way in some regions of the country. But now there exist technologies allowing minimizing environmental impact on the fish growth.

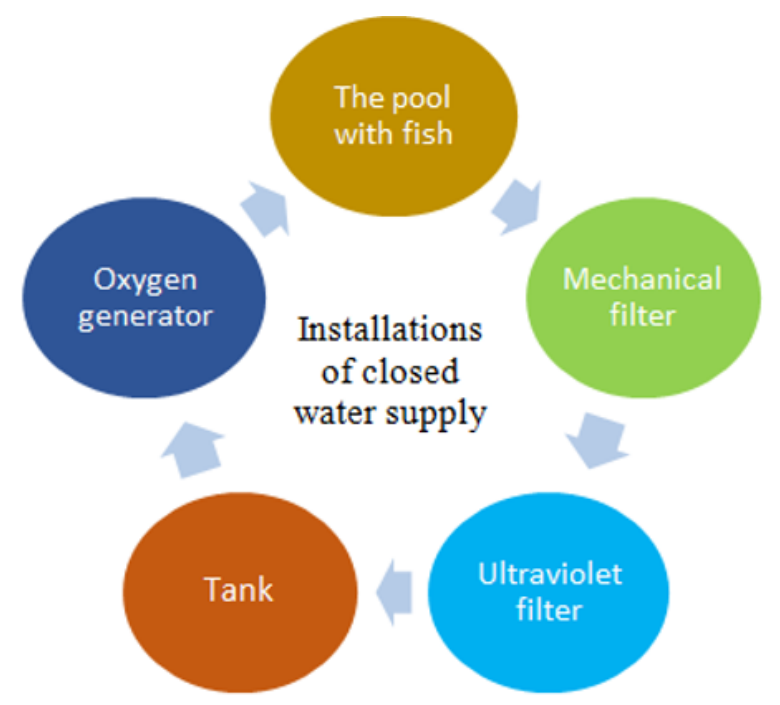

Fig. 1. The basic technological process at closed water supply installation for fish cultivation.

One of the most perspective technologies of fish cultivation is the installation of the closed water supply (ICWS) [1]. These installations appeared in the USA in the middle of the 20th century. Their use was proved by the American national program of restoration of number of natural populations of a trout in northwest states of the USA. Technological capabilities of ICWS allow growing up fish all the year round, at the same time avoiding mass death of whitebait or adult individuals $[2,3]$. To grow up healthy and large fish, it is necessary to improve conditions of its content. For this purpose, we should introduce measurement of concentration of the weighed particles in our automation system.

\section{Methods}

Cultivation of fish in installations of closed water supply is a difficult process, which we will try to deal with [47]. Fish is settled in a special pool in which various devices for maintaining the optimum level of all components, which are important for fish activity, are installed. These fishes were not ill, and their life cycle was not broken. Further, water constantly undergoes filtration and enrichment by oxygen, which helps fishes to spend less energy for breath process and therefore they grow quicker [7]. It is known that oxygen comes through gills and it is required for energy production and proteolysis. Carbon dioxide [8] and ammonia are produced as waste and the undigested forage is discharged in water in the form of excrement, also named as suspended substances [7]. Carbon dioxide and ammonia are emitted in water through gills. As a result, fishes consume oxygen and forage, so water in a system becomes contaminated by excrement, carbon dioxide and ammonia. To eliminate waste discharged by fishes and to add oxygen for maintaining life and health of fishes, water in ICWS needs to be purified constantly $[9,10]$. Therefore from a drain of fish-breeding pools water comes to the mechanical filter, from there to the TechKom biological filter. Further water is aerated by the Oxymat O-20 oxygen generator, from which carbon dioxide is removed again when it moves to fish-breeding pools [11]. It is the basic principle of recirculation. Such conditions imitate the natural ones, keeping health of fishes and not affecting negatively their reproduction. For fish of a specific type a certain temperature condition has to be maintained, in our case the surgeon is in the pool at a temperature of $30-35{ }^{\circ} \mathrm{C}$. Such manipulations stimulate fish to consume more forage,

\footnotetext{
* Corresponding author: cmvorkut@mail.ru
} 


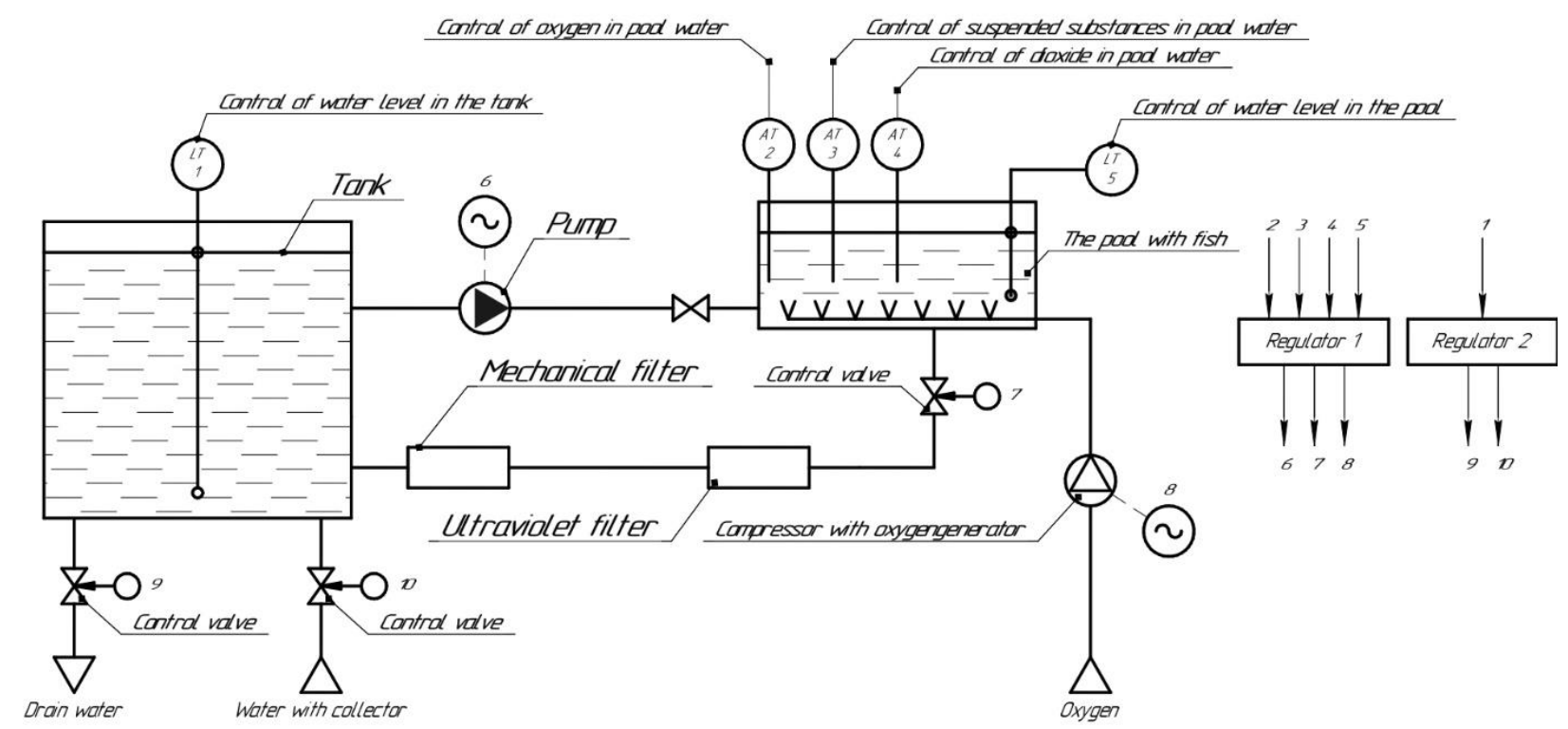

Fig. 2. The functional diagram of automation of the closed water supply installation for sturgeon fishes.

and, in turn, it positively influences the growth rate of whitebait [12].

All these components are extremely important for acceptable functioning of installation. The properly chosen equipment and its uninterrupted operation is a guarantee of successful work of all system shown in figure 2 .

Besides, the requirements on effective use of water resources are imposed to these installations, namely the minimum feed, and use of cooling water. Here we also implement an automatic system of regulation by technological process. We are focusing on the yearround cultivation of hydrobionts in the closed aqua cultural farms, and we exclude the wintering mode, thereby putting in the growth process. This technology is more qualitative, the habitat is better and, as a result, growth rates of fish are higher. For this purpose, we need a software-hardware complex with the OWEN PLC73 controller, and other instrumentation. Besides, qualitatively purified water allows increasing density of fish landing and to use floor spaces more efficiently. Control of technological process operation is exercised by a monitoring system which should include sensors of oxygen level and flow, pressure, temperatures and sensors for environment analysis. Feeding of fishes is automated. In the feeding tank the timer is installed and the portion of feeding is thrown out in a set time, so that fishes receive all useful substances in time. To control and minimize the feed we use the ViSolid-700IQ.

Different types of Grundfos pumps are used for circulation of production water. Pumping of water demands electricity, and to reduce its consumption it is important to set a small height of water supply, and to use efficient and appropriate pumps [4]. Whenever possible, rising of water should happen only once for a recirculation cycle then water flows by gravity through all system back in the pump receiver.

\section{Results}

During our study, we came to a conclusion that for highquality work of installation, it is necessary to hold the following principles of the closed water supply installation operation:

- It is preferable that control of water parameters is performed based on information arriving from sensors of water level, water transparency, oxygen content in water, the content of carbon dioxide in water, water $\mathrm{pH}$ and water temperature.

- It is preferable that water $\mathrm{pH}$ makes adjustment addition in alkali water.

- It is preferable that increase in oxygen concentration in water is carried out by water aeration by air.

- It is preferable that decrease of carbon dioxide concentration in water is achieved by water aeration by air.

- It is preferable that heating of water is carried out by means of the boiler heater.

\section{Discussion}

Automatic equipment will allow fish breeders to completely control all production parameters and to simplify skills of the breeder fish in management of ICWS. Continuous and predictable growth, economy of energy resources, increase in the work efficiency, expansion of managing directors and information opportunities of a system becomes a result of long stable conditions, and will allow the fish breeder to precisely predict when fish reaches a certain stage of development or size. The expenses on its maintaining and technological process visualizing will be decreased [13]. There will be a possibility of drawing up the exact 


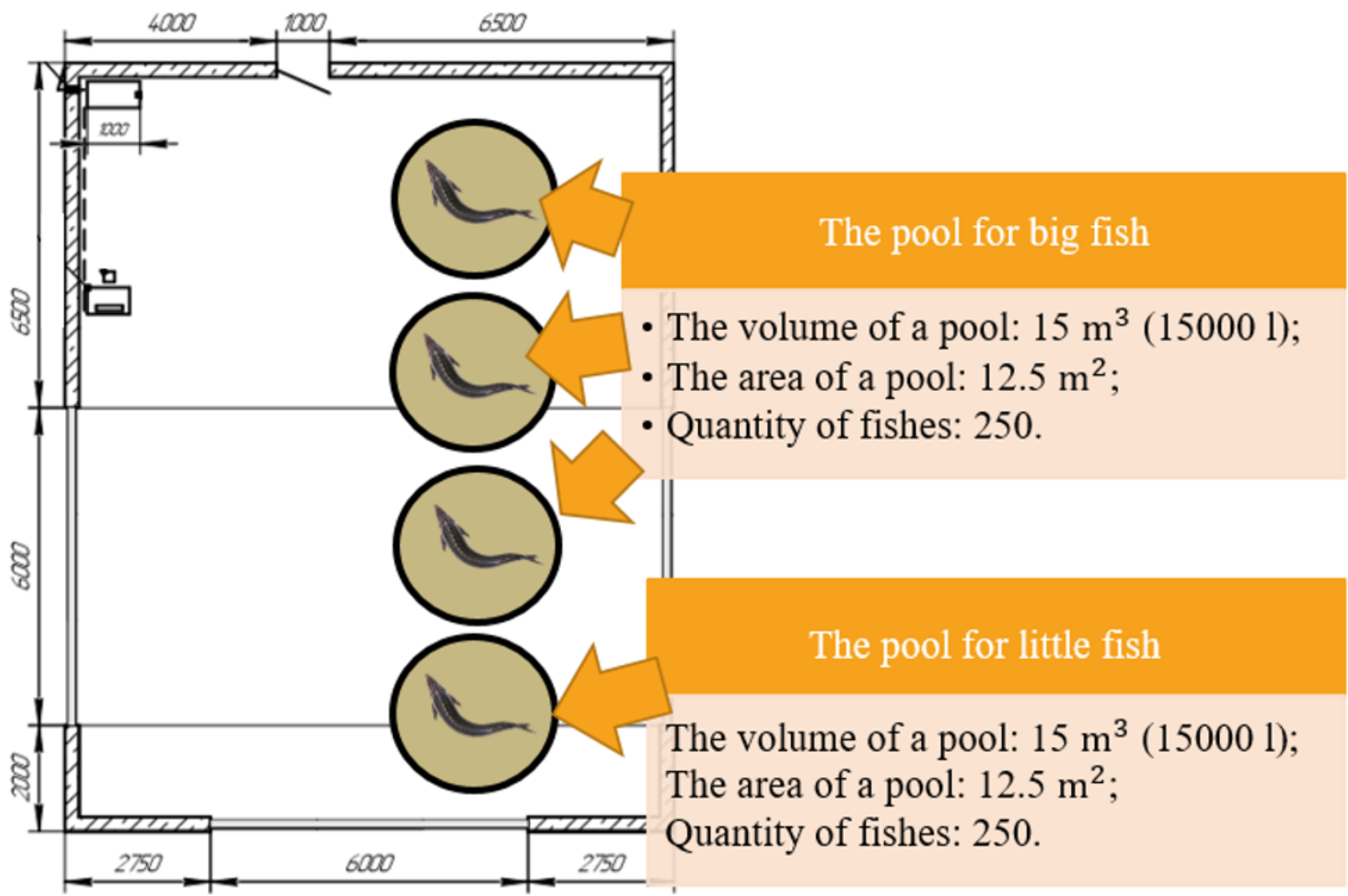

Fig. 3. The plan of arrangement of installation of the closed water supply.

production plan and forecasting the exact time when fishes are ready to their further realization, which will have a beneficial impact on the general management of economy [14].

\section{Conclusions}

We have developed a project to install a closed water supply system, the positive effects of which are listed below:

- In the control system the water parameters are recorded from sensors of water level, transparency of water, oxygen content in water, the content of carbon dioxide in water, water $\mathrm{pH}$ and water temperatures. This will make it possible to keep abreast of all productions processes of systems.

- The received parameters are processed and a task is given to actuators. This will increase the economic impact.

- By creating a favorable habitat for fish, we invest in their health. This will reduce the loss of sturgeon individuals, and affects the weight and quantity of the obtained products.

\section{References}

1. The ICWS model is the guide to design (2016) [http://aquavitro.org/2016/07/09/model-uzvrukovodstvo-po-proektirovaniyui-upravleniyu]
2. D.A. Sadler, A.A. Kokoza, O.N. Zagrebina, V.A. Grigor'ev, Estimation of the productive stock of Russian sturgeon formed in the breeding complex Ltd. AFC "Beluga", 175-182 (2011)

3. Ju.V. Alymov, A.A. Kokoza, O.S. Sergeeva, A. Human, Estimation of the quality of Russian sturgeon fry in relation to reproduction and the problem of produstive stock formation, Vestnik Astrahanskogo gosudarstvennogo tehnicheskogo universiteta. Serija: Rybnoe hozjajstvo, 2, 105-111 (2011)

4. I.F. Pravdin, Guidelines on fish studying, 376 (1966)

5. E.I. Kampen, W.G. Zijistra, Standardization of hemoglobinometry, 6, 538-544 (1961)

6. T.E. Weichselbaum, Determination of total proteins, 7,40

7. G.G. Golodec, Laboratory practicum on fish physiology, 92 (1955)

8. G.F. Lakin, Biometry, 352 (1990)

9. P. Trinder, Determination of glucose in blood using glucose oxidase with an alternative oxygen acceptor. Ann. Clin. Biochem., 6, 24-28 (1969)

10. A.Ju. Kiselev, Biological basis and biotechnological principles of breeding and growing of aquaculture objects in installations with reserved water supply, Abstract of dis. doc. biol. sci., 62 (1999)

11. W. Runia, Disinfection of recirculating water from closed production system, In: Proceedings of the Seminar on closed production systems (1996)

12. Y.A. Khetagurov, Design of automated information processing systems and management, 243 (2015) 
13. S.B. Arsenyev, V.B. Britkov, N.A. Malenkova, Use of technology of the analysis of data in intellectual information systems, Management of information flows, 47-68 (2015)

14. V.B. Britkov, A.V. Smirnitsky, System analysis of the main directions of development of complex corporate control systems, Management of information flows, 85-98 (2013) 